\title{
Postulados filosóficos católicos, repercusiones en el cuidado humano: revisión sistemática
}

\section{Catholic philosophical postulates, implications on human care: a systematic review}

\author{
Katerine Bustamante $^{1}$, Lorena Iñamagua ${ }^{1}$, Tatiana Loja ${ }^{1}$, Liliana Tapia ${ }^{1}$, Deysi Ortiz ${ }^{1}$, Zoila Castro ${ }^{1}$ \\ ${ }^{1}$ Universidad Católica de Cuenca, Ecuador \\ *blinamagual12@est.ucacue.edu.ec
}

DOI: https://doi.org/10.26871/killkana_salud.v4i3.694

\begin{abstract}
Resumen
Resumen: La religión /filosofía católica influye en el cuidado humano, la enfermería como disciplina innata para este propósito, estipula una correspondencia con la religión, de cómo esta impulsa la salud y el bienestar en las personas. Considerando las creencias cristianas, nos ayuda a entender su situación, y otorgar e inducir un cuidado más sensible, de amor y confianza hacia el prójimo, teniendo empatía enfermo o necesitado. Objetivo: Conocer como los principios de la filosofía católica pueden influir en el cuidado humano, desde su atención hasta la recuperación de las personas. Método: Se realizó una búsqueda principalmente en las bases de datos Scielo, Dialnet y SCOPUS, sobre la importancia de la filosófica católica en el cuidado humano. Los estudios otorgados por las fuentes, mediante el análisis del título, resumen y texto completo, se acontecieron finalmente los estudios potenciales para la revisión en función de criterios de inclusión y exclusión, tras un proceso de tamizado. Resultados: La recolección de los estudios acogió 105 referencias, tras un proceso de cribado se excluyeron 92 estudio irrelevantes, concluyendo con la elección de 13 estudios para el análisis cuantitativo que cumplieron con los criterios de inclusión y objetivo de estudio. Conclusión: La filosofía católica en el cuidado humano, precisa la importancia para la dignidad humana, por la sugestiva prevalencia en la salud de las personas. Señala que el cristianismo, es una actividad que emana, la calidez, solidaridad y sensibilidad humana respetando las creencias y valores, encaminados en comprender todas las dimensiones del ser humano, promoviendo la conciencia y desarrollo de actitudes y actividades en virtud del propio cuidado en preservar la salud mediante la vida digna, además el amor al prójimo, ante la enfermedad o necedad de las personas, en brindarle un cuidado de calidad.
\end{abstract}

Palabras clave: Filosofía católica, cuidado humano, enfermería, cristianismo, personas enfermas.

\begin{abstract}
Abstract: Catholic religion / philosophy influences human care, nursing as an innate discipline for this purpose, stipulates a correspondence with religion, of how it promotes health and well-being in people. Considering Christian beliefs, it helps us understand their situation, grant and induce a more sensitive care, of love and trust towards others, having empathy sick or needy. Objective: Know how the principles of Catholic philosophy can influence human care, from their care to the recovery of people. Method: A search was carried out mainly in the Scielo, Dialnet and SCOPUS databases, on the importance of Catholic philosophy in human care. The studies granted by the sources, through the analysis of the title, abstract and full text, were finally followed by potential studies for the review based on the inclusion and exclusion criteria, after a screening process. Results: The collection of studies received 105 references, after a screening process, 92 irrelevant studies were excluded, concluding with the choice of 13 studies for the quantitative analysis that met the inclusion criteria and study objective. Conclusion: Catholic philosophy in human care specifies the importance for human dignity, due to the suggestive prevalence in people's health. He points out that Christianity, is an activity that emanates, the warmth, solidarity and human sensitivity respecting beliefs and values, aimed at understanding all the dimensions of the human being, promoting awareness and development of attitudes and activities under personal care in preserving health through a dignified life, in addition to love of neighbor, in the face of illness or folly of people, in providing quality care.
\end{abstract}

Keywords: Catholic philosophy, human care, nursing, Christianity, sick people. 


\section{Introducción}

Basado en el enfoque de una revisión sistemática, esta investigación pretende analizar la importancia que ha venido teniendo, los principios de la filosofía católica respecto al cuidado humano, su influencia, sobre todo el papel que tienen profesiones que se han dedicado a esta tarea como es la enfermería. ${ }^{1,2}$ Por historia ha sido esta profesión dedicada y responsable de velar por el cuidado y bienestar de la humanidad, además de ser un aspecto de la conciencia humana para su auto cuidado. Los motivos se deben a que las personas en su conjunto social son dependientes de cuidados para mejorar y mantener su salud. En ello la calidad de una asistencia tiene un rol imprescindible, para fomentar el cuidado y bienestar de las personas, como también expedir la educación en la salud. Por lo cual son aspectos que deben ser ejecutados como un derecho prevalente, sin discriminación y enfocados a tal propósito que contemplan, apegado a la compasión, compresibilidad y empatía, de la parte humana que encarnezcan los principios del cristianismo - o filosofía católica, como ente creador del cuidado. ${ }^{3,4}$

La filosofía de la enfermería, y más aun la que sustenta el nombre de filosofía cristiana. No son cuestiones habituales en la mayor parte de los contenidos anunciados, por revistas relativas a la ciencia de la enfermería. ${ }^{5-7}$ Sin embargo tratar de entender, el posible vínculo que existe entre los cuidados de la enfermería y la filosofía católica resultan importantes, la posibilidad de ésta asociación confiere el establecimiento y el intento por averiguar de qué manera se podría fomentar el cuidado humano. En lo cual este artículo está dedicado a los siguientes apartados: cuidado humano, la filosofía cristiana y la conveniencia de su vinculación. ${ }^{8}$

Desde luego el cuidado humano apreciado desde dicho punto de vista, abarca principios éticos, morales y religiosos. En ello la filosofía de la enfermería reside en procurar el cuidado humano, como razón de la praxis profesional, en lo cual no se limita solo a concepciones teóricas, conocimientos y prácticas, que sí bien enriquecen a la disciplina por medio del cuidado, sino ir más allá de este hecho, en otras palabras no solo ser imperante al apartado técnico sino también humano en el contexto de la vida misma. ${ }^{9,10}$ En ello la importancia de contemplar principios de la filosofía católica, enmarcan un cuidado mucho más versátil, factible y gratificante sobre todo de calidad. En lo cual el encargado de cuidar, el bienestar humano, comprende y aprende de sí mismo y del paciente en el contexto sobre el cual se sitúa, que lo llevan a conocer mucho mejor a los individuos como pacientes que requieren de atención, de tal manera que pueden ofrecer adecuadas intervenciones para tal cometido, con calidad, hospitalidad y amabilidad en provecho de mejorar la salud y el cuidado, tanto en forma física, psíquica como social. ${ }^{11-13}$ Siendo considerados como elementos que deben estar en armonía, para lograr el bienestar general en las personas.

Por todo lo enunciado, es pertinente decir que el cuidado se ha convertido en una actividad de satisfacción únicamen- te ante la necesidad de enfermedad de los pacientes, pero este hecho cada vez se aísla más, debido que las interacciones, sean vuelto en atenciones poco acogedoras y solitarias de entendimiento, empatía, sensibilidad y disposición para escuchar. ${ }^{14-16}$ Esto ha alterado la verdadera esencia y razón de la praxis de enfermería obviando su efecto.

Esto es producto, de que a medida que la tecnología ha progresado, esto ha incurrido en carencias en los sistemas y servicios de salud, debido al aumento en la demanda. ${ }^{28,39}$ El exceso de la actividad administrativa y las políticas de las entidades, han aportado al abandono del cuidado de calidad, apuntando y promoviéndose hacia una atención más tecnológica, fragmentada y despersonalizada.

Bajo este aspecto, el estudio impartirá nuevos conocimientos a partir de la metodología aplicada y desde los propios sujetos de estudio que permitirán acrecentar la firmeza de la indagación así como también hacer alusión a los aportes significativos para mejorar el cuidado impartido a las personas desde la óptica de los principios católicos.

Debido a la conformidad del cristianismo se introdujo el cuidado en las personas hacia los enfermeros, con lo cual se acogieron valores en base a una nueva filosofía de la vida, en la cual se concibe el amor al prójimo y la salvación del alma, dejando de lado las riquezas. ${ }^{17,18}$ Dicha perspectiva se encamina a los primordiales destinatarios de los cuidados como son los enfermos y necesitados. Siendo esta filosofía la que inflige en muchas personas y de ahí su importancia, a dedicarse con gran generosidad e imprecisos de conocimientos al cuidado de personas enfermeras en condiciones de pobreza, puesto que fueron admitidos como desperdicios sociales que sucumbían solitarios y sin ayuda correspondiente. ${ }^{19,20}$ Por lo que, tener este aspecto en cuenta dentro de la enfermería acervara la proliferación de la humanidad en formación de la disciplina.

\subsection{Objetivo}

El presente estudio tiene como fin, conocer como los principios de la filosofía católica pueden influir en el cuidado humano, desde su atención hasta la recuperación de las personas.

\section{Métodos}

Esta investigación para su estudio se ciñe en una observación cualitativa y de análisis, haciendo uso de revisiones bibliográficas. En la recepción de los fundamentos teóricos se basaron en aquellas que susciten los postulados de la filosofía católica en el cuidado humano, haciendo hincapié en las personas enfermas y las prestaciones de atención que debe ofrecer un profesional de enfermería, bajo los aspectos éticos, filosóficos, morales y humanos del cuidado de la salud, como también de la relación de los cuidados humanos con el cristianismo, todos estos fundamentos son utilizados como estrategia de inclusión de la información para limitar el estudio con datos de utilidad. 


\subsection{Fuentes de información}

Para poder ser ocupada en esta revisión sistema, se precisa, el análisis y la simplificación de 13 estudios de varias fuentes de información, sobre temas que traten de los principios de la filosofía católica en el cuidado humano. Sobre esto se buscó principalmente información de los últimos 5 años (2016 a 2020) basándonos en todo tipo de documentación científica como; artículos, tesis, revistas y libros, cuya documentación reposa en las bases de datos, repositorios y sitios web de ciencia médica, como fuentes de información, por lo que tienen gran prestación que se apresta para concretar la búsqueda de la información a temas, campo de estudio, año de publicación y autores específicos, siendo relevante para la investigación estas medidas. Entre las fuentes bibliográficas de estudio tenemos:

- Bibliotecas de universidades como; la Universidad Libre de Colombia y la Universidad de Huelva México, y como páginas científicas El Instituto de Bioética de la Universidad de Finis Terrae y la Fundación INDEX junto con la revista de enfermería ENE.

- Como bases de datos se aplicaron a Scielo, Dialnet, ScienceDirect, SCOPUS y NCBI.

- Para el desarrollo en el acopio de tal información se estipulo en los periodos de los meses de abril mayo del 2020, para los fines de búsqueda pertinentes (desde el 24 de abril al 5 de mayo la última búsqueda). Haciendo uso de fichas bibliográficas como medio de registro de las fuentes de información confiadas para este tipo de revisión metódica.

\subsection{Criterios de Selección}

Respecto a la elegibilidad se definió lo siguiente, para precisar de documentación valida, obviando aquellas que no cumplan con tales condiciones de inclusión, estas son:

1) Como población se incluye a todas las personas con petición de los cuidados humanos.

2) La información de las publicaciones recabadas debería estar en los lapsos de emisión entre 2015 a 2020, para que el estudio sea de novedad científica.

3) Tener acceso a documentos completos, en los artículos, evitando desperdicio a registros de validez.

4) Para hacer reproducible la indagación, que el título, resumen o palabras clave contengan las frases de postulados filosóficos católicos y su efecto en el cuidado humano, concepto que deberá ser de carácter diverso sin extremarse a situaciones particulares sino más bien universales.

5) Como idioma y a efecto de enriquecer el estudio, con opiniones diferentes pero alusivas al tema, que sean en inglés, portugués y español.

En este proceso se suprimieron, fuentes de información que no centren su análisis sobre los postulados de la filosofía católica respecto al cuidado humano, precisamente documentos cuyos temas no aborden la concepción básica expuesta, dada la evidencia de similitud de conceptos, pero que no confieren como ámbito de estudio los cuidados humanos en el prospecto de la salud.

\subsection{Método de búsqueda}

Como estrategia para la captación de la información, esta estuvo afianzada a variables, que han sido fundamentales para este estudio, dado que permiten hacer búsquedas mediante los; títulos, autores, tipo de revistas por la diversidad de disciplinas y años de publicación con lo cual se obtiene información de calidad y de variedad concorde al tema de estudio. Para ello, el procedimiento de búsqueda estuvo basado en hacer uso de filtros y key Word (como: Postulados filosóficos católicos, cuidado humano o por el uso de palabras semejantes o sinónimos) y los límites de indagación, años de publicación, idioma y tipo de documento, a través del filtro siendo algunas de las herramientas, que permiten hacer la exploración al completar los campos de título y resumen, que suscita la base de datos para la recuperación de reseñas, dispuestas en el contenido de los artículos. Otras de las virtudes como estrategia de búsqueda, también es el uso de conectores lógicos (principalmente OR, AND y NOT) con los cuales se pudo delimitar la búsqueda haciéndola más concisa y exhaustiva, así también el uso de índices de búsqueda que tienen un efecto similar en combinación con conectores y condiciones de búsqueda; título o resume. Permitiendo realizar búsquedas especiales, los cuales se identifican por códigos; ti: título del artículo, au: autor, KW: palabras clave, country: país, entre otro.

En el caso de la base de datos Scielo, permite realizar la investigación de artículos por palabras del resumen, títulos y limitar los años de publicación, el siguiente algoritmo permite definir el esquema de búsqueda de información de calidad e interés del tema:

Expresión: Postulados filosóficos católicos Or Cristianismo en el cuidado humano

Filtros aplicados: cluster publications:(Año de publicación: 2016) (Año de publicación: 2020).

En este procedimiento recalcamos la delimitación del tema por palabras clave; postulados filosóficos y cuidado humano, periodo de publicación y conectores para relacionar las palabras clave, que acogen las concepciones principales de la investigación.

\subsection{Selección de estudios}

Mediante los criterios de selección y estrategias de búsqueda aplicados en las fuentes de datos, se llegó a la recolección de varios artículos considerados elegibles. Sin embargo para respaldar a que el proceso de selección sea transparente, y que permita identificar los potenciales estudios y reducir el riesgo de información irrelevante. Se analizaron los estudios y se los clasificó como incluidos y excluidos.

La revisión comprende de etapas (Figura 1), como la eliminación de artículos replicados, la lectura del título, resumen y palabras claves, las cuales precisan los estudios 
y que estos estén en concordancia con el objetivo de investigación (Postulados de la filosofía católica en el cuidado humano) para ser escogidos caso contrario descartados, luego de esto se hizo una revisión considera más exhaustiva y la última, que es la lectura del texto completo. Dando como resultado final de este proceso sucesivo de cribado, un total de 15 estudios de investigación seleccionados para esta revisión sistemática en la cual se apoyará su desarrollo.

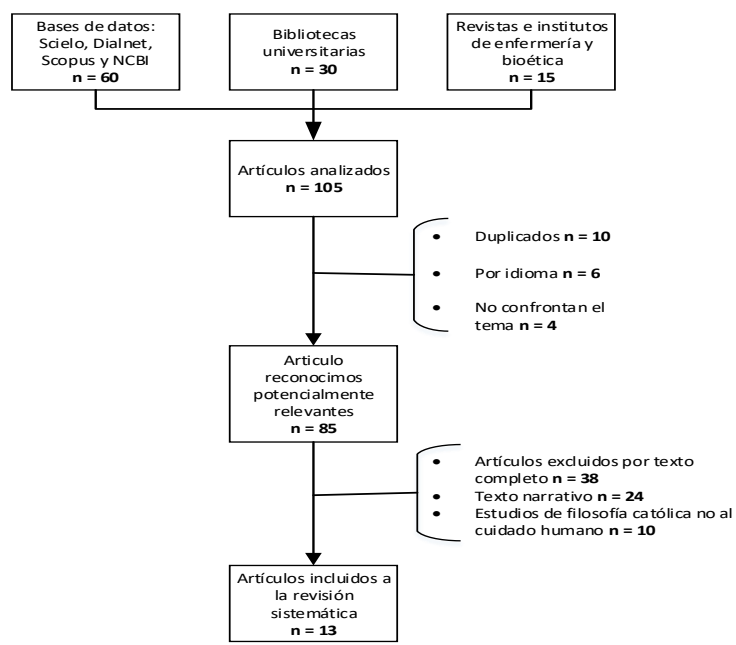

Fig. 1: Selección de estudios de filosófica católica implicada en el cuidado humano

Fuente: Autores

\subsection{Proceso de extracción de los datos}

En la sustracción de los datos, se determinó en primera instancia la evaluación de los estudios incluidos de forma independiente por los miembros del grupo de investigación. En sí, la validez de los resultados obtenidos, fue puesta a consideración siendo socializados los datos, de forma que las diferencias originadas fueron discutidas y solucionadas por común acuerdo.

De tal forma que los datos a extraer tuvieron en cuenta los atributos más relevantes de los artículos incluidos; como autor, fecha de publicación y tipo de estudio, permitiendo apreciar con claridad las aportaciones de los resultados de aquellos relacionados con los principios de la filosófica católica en el cuidado humano desde la óptica de la enfermería. Siendo pertinente para este proceso el uso de hojas electrónicas en formato Excel, en las cuales se recogieron los datos (véase la Tabla 1).

Tabla 1: Extracción de datos de los artículos incluidos

\begin{tabular}{|c|c|c|c|c|}
\hline Tema de estudio & Autor & Año & País & $\begin{array}{c}\text { Metodología } \\
\text { de estudio }\end{array}$ \\
\hline $\begin{array}{l}\text { Pasado y presen- } \\
\text { te de la función } \\
\text { enfermera en el } \\
\text { acto del cuidado }\end{array}$ & $\begin{array}{l}\text { Dandicourt } \\
\text { Thomas, Caridad } \\
\text { Hernández } \\
\text { Valdez }\end{array}$ & 2020 & Ecuador & $\begin{array}{l}\text { Revisión } \\
\text { sistemática }\end{array}$ \\
\hline
\end{tabular}

Tabla 1: Extracción de datos de los artículos incluidos...continuación

\begin{tabular}{|c|c|c|c|c|}
\hline Tema de estudio & Autor & Año & País & $\begin{array}{c}\text { Metodología } \\
\text { de estudio }\end{array}$ \\
\hline $\begin{array}{l}\text { Valores } \\
\text { religiosos y } \\
\text { morales como } \\
\text { factores en el de- } \\
\text { senvolvimiento } \\
\text { de enfermería }\end{array}$ & $\begin{array}{l}\text { Puelma C., Dora } \\
\text { Donoso M., Bea- } \\
\text { triz }\end{array}$ & 2018 & Brasil & Cualitativo \\
\hline $\begin{array}{l}\text { El cuidado y la } \\
\text { enfermería }\end{array}$ & $\begin{array}{lr}\text { Rocha, } & \text { Patricia } \\
\text { Kuerten } & \text { Do } \\
\text { Prado } & \\
\end{array}$ & 2016 & Brasil & $\begin{array}{c}\text { Cualitativo y } \\
\text { descriptivo }\end{array}$ \\
\hline $\begin{array}{l}\text { Enfermería en el } \\
\text { mundo cristiano }\end{array}$ & Aquichan & 2015 & Colombia & $\begin{array}{c}\text { Revisión } \\
\text { sistemática }\end{array}$ \\
\hline $\begin{array}{l}\text { La enfermería y } \\
\text { la religión }\end{array}$ & Sanz, González & 2015 & Ecuador & $\begin{array}{c}\text { Observación } \\
\text { y análisis }\end{array}$ \\
\hline $\begin{array}{l}\text { Fundamentos } \\
\text { fenomenológicos } \\
\text { para un cuidado } \\
\text { comprensivo de } \\
\text { enfermería }\end{array}$ & $\begin{array}{l}\text { Rivera, María } \\
\text { Soledad Herrera, } \\
\text { Luz María }\end{array}$ & 2017 & Chile & Descriptivo \\
\hline $\begin{array}{lr}\text { Filosofía } & \text { de } \\
\text { la ciencia del } \\
\text { cuidado analogía } \\
\text { del mito } & \text { de } \\
\text { la caverna } & \text { de } \\
\text { platón con } & \text { la } \\
\text { profesión } & \text { de } \\
\text { enfermería } & \\
\end{array}$ & $\begin{array}{l}\text { Díaz Rentería, } \\
\text { María Guadalupe }\end{array}$ & 2018 & Colombia & $\begin{array}{l}\text { Revisión } \\
\text { sistemática }\end{array}$ \\
\hline $\begin{array}{l}\text { Bioética y cato- } \\
\text { licismo: dificul- } \\
\text { tades en torno } \\
\text { a la constitución } \\
\text { de una identidad } \\
\text { colectiva }\end{array}$ & $\begin{array}{l}\text { Gabriela Irrazá- } \\
\text { bal }\end{array}$ & 2018 & Panamá & $\begin{array}{l}\text { Revisión } \\
\text { sistemática }\end{array}$ \\
\hline $\begin{array}{l}\text { Cuidado } \\
\text { humanizado } \\
\text { de enfermería } \\
\text { según la teoría } \\
\text { de Jean Watson }\end{array}$ & $\begin{array}{l}\text { Rosar Gurrero } \\
\text { Ramirez, Mónica } \\
\text { Elisa Meneses }\end{array}$ & 2019 & Ecuador & $\begin{array}{c}\text { Observación } \\
\text { y análisis }\end{array}$ \\
\hline $\begin{array}{l}\text { Modelo de cui- } \\
\text { dados de enfer- } \\
\text { mería para un en- } \\
\text { torno multicultu- } \\
\text { ral }\end{array}$ & $\begin{array}{l}\text { González, Daniel } \\
\text { Leno }\end{array}$ & 2016 & Ecuador & Descriptivo \\
\hline $\begin{array}{l}\text { Cristianismo y la } \\
\text { medicina }\end{array}$ & $\begin{array}{l}\text { Dueñas, Ángel } \\
\text { Fernández }\end{array}$ & 2018 & Colombia & Descriptivo \\
\hline $\begin{array}{l}\text { La religión y su } \\
\text { influencia en las } \\
\text { conductas de sa- } \\
\text { lud }\end{array}$ & $\begin{array}{l}\text { Rodríguez, Yoja- } \\
\text { nán Carrasco }\end{array}$ & 2019 & Ecuador & $\begin{array}{l}\text { Revisión } \\
\text { sistemática }\end{array}$ \\
\hline $\begin{array}{l}\text { Introducción } \\
\text { a la relación } \\
\text { entre cuidado y } \\
\text { filosofía }\end{array}$ & $\begin{array}{l}\text { Jesús Pinto } \\
\text { Freyre, } \\
\text { Santamaría } \\
\text { García, } \\
\text { José María } \\
\text { Santamaría } \\
\text { Pérez, Adrián } \\
\text { Martínez Botija, } \\
\text { Sergio }\end{array}$ & 2020 & Uruguay & $\begin{array}{l}\text { Descriptivo y } \\
\text { cualitativo }\end{array}$ \\
\hline
\end{tabular}

Nota: «En esta tabla se describe la información relevante de cada estudio seleccionado, la información expuesta fue adaptada por los autores en base a los fuentes de estudios incluidos en esta revisión. Tomada de:(Dandicourt Thomas et al., 2017; Dueñas, 2016; Irrazábal, 2015; Momennasab et al., 2019; Neil Cope et al., 2016; Puelma C. \& Donoso M., 2014; Quintero Laverde, 2015 Rivera \& Herrera, 2016; Rocha et al., 2019; Rodríguez, 2015; G Sanz, 2016; Tapia \& Guzmán, 2018; Żołnierz \& Sak, 2017)»

\subsection{Lista de datos}

Las variables de búsqueda que se emplearon en los estudios seleccionados, han permitido precisar de información de calidad y relevancia, respecto a los principios de la 
filosofía católica en el cuidado humano, para tal propósito fueron diseñadas estas variables mediante la estrategia Población, Intervención, Comparación y Resultado (PICO) (véase la Tabla 2), dado que esta toma en cuenta todas las características del objetivo de investigación y criterios de selección, con lo cual nos permitió obtener datos de novedad e interés.

Tabla 2: Lista de variables de búsqueda en base a la estrategia PICO

\begin{tabular}{|c|c|c|c|}
\hline$P$ & I & $\mathrm{C}$ & $\mathrm{O}$ \\
\hline $\begin{array}{l}\text { Impacto de la } \\
\text { filosofía católi- } \\
\text { ca en las perso- } \\
\text { nas }\end{array}$ & $\begin{array}{l}\text { Cuidado } \\
\text { humano y el } \\
\text { bienestar de } \\
\text { las personas }\end{array}$ & $\begin{array}{l}\text { La empatía por } \\
\text { las personas } \\
\text { enfermas }\end{array}$ & $\begin{array}{l}\text { Reducir las } \\
\text { atenciones } \\
\text { frías hacia los } \\
\text { pacientes }\end{array}$ \\
\hline \multirow[t]{2}{*}{$\begin{array}{l}\text { El cristianismo } \\
\text { en la enferme- } \\
\text { ría }\end{array}$} & $\begin{array}{l}\text { La calidad de } \\
\text { asistencia en la } \\
\text { recuperación } \\
\text { de las personas }\end{array}$ & $\begin{array}{l}\text { Ceñirse a } \\
\text { la práctica } \\
\text { solamente } \\
\text { técnica de la } \\
\text { enfermería }\end{array}$ & $\begin{array}{l}\text { Mejorar la ca- } \\
\text { lidad de aten- } \\
\text { ción y flexibi- } \\
\text { lidad de recu- } \\
\text { peración de las } \\
\text { personas }\end{array}$ \\
\hline & & & $\begin{array}{l}\text { Formación de } \\
\text { profesionales } \\
\text { de enfermería } \\
\text { con valores } \\
\text { éticos, morales } \\
\text { y cristianos. }\end{array}$ \\
\hline
\end{tabular}

\subsection{Riesgos de sesgo de estudios individuales}

Dentro de los métodos ocupados para reducir el nivel de riesgo por sesgo en la información. Es permitir evitar errores sistemáticos a fin de aislarse de los propósitos de la investigación y de la población de análisis, que serán ocupados dentro del tema central referente a los principios de la filosofía católica en el cuidado humano vistas desde la concepción de la enfermería, sobre los estudios incluidos.

En ese sentido ha sido pertinente optar por estrategias que permitan la evaluación del riesgo de sesgo, para lo cual ha sido conveniente establecer el uso de la estrategia por generaciones aleatorias y la escala de calificación por dominio (determine en alto o bajo nivel de sesgo), otorgadas por la herramienta de colaboración Cochrane. Por lo que estas estrategias serán aplicadas a nivel de los estudios y de forma individual en cada documento, de tal forma que se presida de resultados fiables en función de la respectiva validez de los datos para así concebir los conceptos relevantes, que permitan la síntesis de la información la cual se representa por porcentajes limitantes en escalas de máximo y mínimo.

\subsection{Medidas de resumen}

Dada la extensibilidad de los contenidos en los estudios incluidos, es necesario el aporte de herramientas, que consoliden los resultados de los estudios primarios en una sola representación. Para lo cual la práctica estadística permite juntar varios estudios en un solo gran estudio, como modo de síntesis cuantitativa.

Para el efecto nos hemos permitido acoger como medida de resumen la técnica Odd Ratio, la cual aporta en forma probabilística sobre la relevancia de un resultado, respecto a la irrelevancia de otro. En el aspecto de la filosofía católica y el cuidado humano; podemos decir aspectos de validez como ayudaría en la asistencia de la enfermería la adopción de principios católicos, en la recuperación y atención sanitaria, y otros aspectos como la hospitalización, el tratamiento y ambiente de confort y sensibilidad por las personas enfermas. Por lo que estos criterios podrían ser combinados por métodos estadísticos, de tal manera que podemos armonizar los diferentes resultados en una representación común, de tal forma que nos permiten situarnos y dar pertinencia, fiabilidad a los datos obtenidos, dando a conocer así los riesgos relativos, al cabo de valorar la precisión de los resultados en los artículos.

\subsection{Síntesis de resultados}

En la manipulación y combinación de los datos de importancia de los estudios, a fin de hacer una valoración de la eficacia de los resultados, sea a estipulado el establecer como técnica el meta análisis, con el cual podemos hacer el cotejamiento de los contenidos respecto a la semejanza y diferencia de las evidencias encontradas (homogeneidad y heterogeneidad). Para así definir las limitaciones del estudio y la interpretación e implicación de los resultados, con el objeto de minimizar los errores y concertar los diferentes resultados.

En este análisis se representara a los resultados de la evaluación del meta análisis, través del intervalo de confianza (CI al $95 \%$ ) y el cegamiento ( $\mathrm{p}<0.05)$ cuyas valores son estándares, que permitirán observar el nivel de validez de los datos en los estudios seleccionados.

\subsection{Riesgos de sesgo entre estudios}

En esta intervención, se ha podido observar la importancia de la evaluación de la calidad en los diversos estudios, para la validad y confianza de la información, en lo cual detectar sesgos en los artículos generara las apropiadas expectativas de la investigación, es así para que para el tema de esta investigación, se ha identificado algunos tipos de sesgos como de publicación, información y selección en los artículos (12, 15 y 20). Los cuales aportan y previenen errores como en los lapsos de las publicaciones de los artículos y permiten realizar la selectividad de la información.

Ante esto se ha definido una clasificación en función del riesgo de sesgo; alto, bajo e indeterminado riesgo de sesgo, que mediante el acoplamiento con base a la metodología del diseño han podido ser analizados pertinentemente por los autores de manera individual, habiendo un conceso para definir la homogeneidad de los resultados en los estudios primarios.

\subsection{Análisis adicionales}

Como análisis adicional de esta revisión sistemática, se pretende exponer datos descriptivos de la filosofía católica en la enfermería al cabo de conocer cuál es el beneficio percibido en atención de las personas y las conductas de salud, así como los motivos de por los cuales las atenciones 
se vuelven frías y poco confiables que se alejan de los principios de cuidado humano. Para el efecto se realizará el análisis por subgrupos de acuerdo a las características pertinentes de cada uno, haciendo la agrupación de los artículos seleccionados.

\section{Filosofía del Cuidado Humano}

Desde el comienzo de la humanidad la enfermería, ha venido dedicándose a velar por el cuidado y preservación de la salud de las personas, consagrándose como función primordial de esta profesión. ${ }^{21,22}$ Acompañada de principios filosóficos, está disciplina tiene en cuenta consideraciones éticas y procesos encaminados a salvaguardar el bienestar humano mediante la práctica del cuidado. Por lo cual se remite a la existencia humana constituyendo una condición primitiva, en el cual cada individuo preserve la vida precedidas de actos consientes en lo cual se involucra la enfermería estando al servicio y dispuesta, en forma consiente y con el conocimiento de apelar al cuidado por el otro ser en un vínculo de alteridad.

Ubicándola bajo la óptica filosófica, el cuidado de la salud se apoya en bases y cuestiones de principios que aluden este concepto. ${ }^{23}$ Es así que constituye un factor inherente dentro de las estructuras sociales a tener una salud física, psíquica y social, cuya mejora y goce depende del cuidado (enfermería). De hecho todo individuo, comunidad y familia (personas de todas las edades y clases sociales) requieren como derecho para posibilitar la calidad de vida y bienestar. ${ }^{16,24,25}$

Así la filosofía de la enfermería, es un factor imprescindible en la civilización humana, su propósito es ofrecer una mejor calidad de vida a las personas, por el hecho de que la salud está concebida, como el fundacional necesario de la vida pública de cualquier individuo, ocupándose, en brindar servicios, recursos y cumplir derechos estipulados innegables de cada individuo concerniente al cuidado de la salud. ${ }^{25,26,38}$

Por ende la práctica del cuidado humano, es la razón en esencia del quehacer profesional de enfermería. (Ferreres, 2017) La filosofía de este hecho elemental, precisa de reflexionar sobre sus anomalías, dado que son las bases que contribuyen a formar conocimiento y fundamentar la identidad de este campo. Por ello el individuo es el sujeto de cuidado, y como tal implica vínculos intersubjetivos y de experiencia que hacen particular la acción del cuidado. ${ }^{27-29}$

Es así que la asociación, en la formación - cuidado, es necesaria porque la formación es garantía de la calidad del cuidado ante una persona, de esto se desprende que la interacción entre el oficio de enfermería y paciente debe ser mutua y de confianza, poniendo de manifiesto la insistencia cristiana o católica. ${ }^{14,16,24}$ No solo ofrece la asistencia sino también de conocer y sensibilizar por lo que pasa el paciente, de una u otra forma esto facilita aún más dicho aspecto de cuidado en base a un ambiente de confort. ${ }^{8,23,30}$ Los profesionales de la rama deben saber manejarse en aspectos de cómo; saber convivir, compartir sentimientos y crear vínculos afectivos, que los lleven al intercambio de información, conocimiento y vivencias. Para lograr el cometido de cuidado que necesita una persona enferma.

Desde la formación para la dedicación al cuidado humano, la enfermería involucra varias concepciones, que no solo se centran en el confín académico, sino que van más allá, desde principios ético científicos, valores y moral, actitud crítica, personalidad subjetiva, conocimiento, creatividad y principios espirituales. ${ }^{5,26,31}$ Tanto que la concepción cristiana, impulsa desde esta perspectiva, la responsabilidad social, como factor que incentiva la divulgación del bienestar y cuidado humano.

Todo esto, juega un papel vital bajo el concepto del cuidado. Beneficia la calidad de asistencia mejorando la situación del cuidado de las personas, dónde se promulgue la equidad intergeneracional, el respeto y la armonía con la naturaleza, siendo aspectos importantes que se apiadan y solo tienen la intención del cuidado humano en condiciones de dependencia a cualquier persona. ${ }^{28,32,33,39}$ Para el logro de mejores niveles de bienestar en la gente, siempre encaminadas al cuidado de la salud y atención, siendo los roles imperantes de este ámbito. ${ }^{12,34}$ Hacer conciencia de este aspecto y el autocuidado son primordiales dentro del cuidado humano, porque este está representado en categorías; El sujeto y persona, el ser, enfermedad y conciencia de la vida y muerte.

\section{La religión en el cuidado humano}

Peculiarmente la enfermería y la filosofía católica o religión cristiana, han estado en recíproca interacción desde la concepción del cuidado humano. (Blanco Enríquez et al., 2019) En términos precisos contempla la ética tanto en la atención como cuidado de la vida humana, en el ámbito biomédico. Esta estimación surte por la noción de que la fe, es abordada como un factor de solvencia a problemas del sentido moral y de razón del hombre. ${ }^{16,35,36}$ En vista de ello la ética cristina es otro elemento primordial, sus aportes hacen posible la apreciación desde diversas racionalidades y cosmovisiones vigentes en la sociedad contractual.

Resulta oportuno considerar que el enfoque cuantitativo, desde el cual es comprendida la enfermería y sobre la cual se ha fundado, no es suficiente para concebirla completamente. ${ }^{13,33,37}$ Al ser la salud humana apoyada mediante el cuidado, esta área de aplicación precisa de conocimientos basados en la empatía de la naturaleza humana y la reacción hacia el entorno, dado que muchas veces es un tema poco profundizado a pesar de que podemos aprender y comprender de ello, sobre las creencias, religión y estigmatismos de la humanidad, al cabo de sustentar la ciencia del cuidado humano en la enfermería. ${ }^{3,4,38}$ Es así que esta base considera también importante para su impulso y progreso la fenomenología, sobre la cual se instaura el interés de contribuir con el cuidado integral estribado en las necesidades incluyentes de cada persona.

La enseñanza social que otorga la iglesia católica constituye un imperante tesoro de sabiduría en la forma de 
forjar una sociedad justa y de vivir una vida de santidad por sobre los desafíos de la sociedad contractual., $12,19,23$ Puesto, que la enseñanza de la sociedad religiosa actual, se ha conformado a través de una tradición de legados; documentos, papales, conciliares y episcopales. Comprender el legado de los escritos, nos permite concebir de mejor forma y plenamente la relevancia e imprescindibilidad de esta tradición. Esta reflexión apela e incide en varias temáticas claves, que están centradas en torno a la esencia de la práctica social católica. ${ }^{13,26,32,35,39}$

Es propicio e inevitable, inspeccionar filosóficamente estos conceptos del cuidado y de poder adéntranos en materia de los enunciados filosóficos a cabo de conocer hacia donde nos pueden orientar. ${ }^{40-42}$ Sobre lo cual respaldan y sustentan sus autores., ya que ello posibilita la determinación de propiedades y particulares propias del cuidado humano que se desenvuelven en una práctica bien definida, teniendo esto secuelas inmediatas en la salud de las personas. Ante ello, la aplicación de la perspectiva de los estudios en este campo como Kikushi y Simmons, ${ }^{43}$ contribuyen para la realización del análisis filosófico desde diversos puntos de vista del cuidado de enfermería, consintiendo la reflexión sobre diferentes dimensiones; como la ontológica, epistemológica y éticas de la enfermería.

Podríamos partir de que los cuidados de la enfermería, serían aquel conjunto de atenciones que facilitan las enfermeras a las personas, mediante una correspondencia profesional dada en cualquier lugar y circunstancia en la que se encuentre. ${ }^{29}$ Por lo tanto cuando se trata, de la formación de futuros profesionales de enfermería, es preciso aclarar que se está discutiendo de la configuración del núcleo conceptual y actitudinal de cada profesional, algo que resulta esencialmente importante por sobre cualquier dominio tecnológico en el enfermero, pertinente a lo concebible al tipo y calidad de los cuidados que luego serán capaces de prestar, de forma oportuna y correspondientemente. ${ }^{1,11,28,31}$

Por otra parte, y persistir en el avance se debe tener en cuenta las aportaciones que puede otorgar y de la cual podemos aprender de la filosofía cristiana, puesto que la hace digna de ser tomada en consideración incluso ante situaciones difíciles de la vida. ${ }^{32,40,44,45}$ Por lo que el interés de está prevalece, en que nos enseña a vivir ya que se apega a un paradigma de la sabiduría antigua forjada a través de años de existencia, pudiendo ser adquirida por quienes todavía aún no son ancianos, a partir de lo cual es prometedor porque puede ayudar y tener sentido, en momentos difíciles, pero la atención no solo está concentrada en este aspecto, sino también en la vida de los demás. ${ }^{1,2,8,13}$ Pues al asumir que la principal función de la filosofía es aprender a vivir, la enfermería requiere apremiadamente de ella, de forma que si tanto los que son cuidados como los que cuidan necesitan aprender a vivir, y estos últimos, además a vivir cuidando. ${ }^{17,27,30,33}$

\subsection{Religión y antropología en las conductas de salud}

En el ámbito concorde al tratado de la salud, se orienta a determinadas conductas en las personas, donde por varias razones y desde hace mucho diferentes religiones han intentado regularlas. La relación que persiste entre la conducta humana y la religión, se la preside desde hace siglos, las formas concretas entorno al comportamiento social, han sido observadas desde un punto de vista científico y exhaustivo, de forma concluyente no se puede precisar, de que la religión pueda influir en la salud de las personas, por lo que es un tema que sigue en debate. ${ }^{21,34,38}$

Cabe mencionar que los estudios desarrollados exclusivamente se fundan en la evolución de la asistencia de los servicios religiosos, que resulta en cierta medida en hallazgos poco confiables y verosímiles. ${ }^{4,42,44}$ No obstante, existen estudios más actuales que tienen en cuenta varios enfoques como en el aspecto; sociodemográfico, la solidaridad económica y social y conductual. Cuyos fundamentos han sido preconcebidos en base a principios inherentes de la religión como la fe, la plegaria y la reflexión. ${ }^{7,17,19,30,45}$

Las prácticas y rituales religiosos, son considerados como acondicionadores que pueden influir de manera inmediata o interactiva en los estereotipos de vida, a los creyendo de una religión en concreto. En si el impacto de este factor se sitúa en fomentar la salud, razón por la cual se entiende que la práctica católica asocia a procederes más saludable en los creyentes, que en la mayoría de las religiosidades tiene creencia en la manifestación par del cuerpo y el alma. ?,4,22,34 En lo que confiere a la apreciación de la parte espiritual o religiosa, se entendería como el tratado del alma siendo la parte fundamental y sagrado de la existencia humana. Donde el cuerpo bajo el aspecto religioso, podrían admitirse como algo terrenal una mera parte que consigna la vida espiritual, por lo que es atribuido como elemento relevante incluso sagrado, como un organismo de nuestro cuerpo que debe ser cuidado para otorgar una mejor calidad vida tanto en forma intrínseca como extrínseca. ${ }^{30,32,33,41}$ Debido a que Dios es la representación de la bondad, carisma, solidaridad, pureza y consagración, indican que la religión espera en sus creyentes esa misma característica de una condición de vida sana, como Dios lo muestra y espera para alcanzar la salud.

Las diferentes religiones tiene como propósito común, en sus devotos, de invitarles a la práctica de un buen proceder que se orientan en beneficiar la salud del cuerpo, que atienden a estilos de vida más saludable, donde sea predilecta al consumo de ciertos alimentos y repruebe otros, o el consumo de bebidas o sustancia que sean nocivas para el cuerpo., el desarrollo de este tipo de comportamiento suponen una asociación en aprovecho para la salud del alma constituida en el cuerpo como lo más sagrado. Dentro de toda cultura religiosa, la comunión espiritual, la asistencia de actividades religiosas, la contribución y apoyo comunitario, hacen a una mejor persona en todos sus aspectos. ${ }^{13,15,19,39}$ 
La evidencia documentada en varios estudios, demuestran que la conducta humana influida por el aspecto religiosa, favorecen al bienestar y la salud de las personas lo cual resulta un hecho conocida desde hace tiempo, siendo una concepción impartido por parte de la psicología de la salud, en dar a conocer el apartado del comportamiento saludable frente a su contrario los de riesgo. ${ }^{12,21,24,38}$ En referencia al cuidado humano, asume un fenómeno en torno a aspectos psicológicos, biológicos, sociales, subjetivos, cognoscentes, emocionales, conativas, psicodinámicas, psicofisiológicas y conductuales. Tradicionalmente es posible señalar las limitaciones dadas por la religión, desde aprobar el consumo de un determinado alimento a causa de no ocasionar una ofensa divina o un perjuicio a la moralidad, por encima de este enfoque la religión encamina fragmentos en calidad preventiva de la salud física y psicológica. ${ }^{11,19,30,32,33}$

En fin las religión en sus devotos, induce a la realización de conductas concretas, que se fundamentan en las creencias de fe que encaminan a la espiritualidad, que bien dicho sea de paso en verdad ese modo de comportamiento se lo utiliza por sus prestaciones en provecho de la salud humana..$^{2,12,22,26}$ No obstante, a diferencia de la religión teísta, la dogmas son asignadas por el deseo de Dios al cual catalogan como "La Palabra de Dios", donde la pretensión de la figura divina es que sus religiosos dispongan de salud, a razón de conservar su vida y dignidad en lo cual sus fieles aprueban sin vacilación, porque según su fe Dios es el ser supremo y de poder divino que los observa, protege y vela por su bienestar. Sin embargo, esto no tiene el mayor respaldo de autenticidad desde una perspectiva imparcial, pues se sabe que los escritos fueron creados por el ser humano, por lo cual se considera que es una aspecto místico, acogido desde épocas remotas por las personas. ${ }^{8,13,19,27,30,39} \mathrm{Sin}$ embargo, la objetividad de investigaciones hechas desde una apreciación antropológica y sociológica, infiere que los hechos recopilados en los escritos religiosos, manejan dos hipótesis que pudieron ser alterados a la largo del tiempo o fueron acoplados a diferentes entornos por su geografía y cultura. $5,17,33,37,41$

\section{Resultados}

\subsection{Selección de estudios}

Durante la búsqueda en las fuentes de datos se recopilo 105 referencias, que fueron acontecidas gracias a las estrategias de búsqueda. Una vez obtenidos los artículos se procedió con los respetivos procesos de tamizado. Para ello se fijaron los criterios de inclusión y exclusión, y en base a un análisis de las referencias. Se excluyeron 10 estudios por duplicados, 6 por idioma que no correspondía con los aceptados para esta revisión que eran en inglés y español, posterior a esto se analizó los artículos por tema y resumen eliminando 4 estudios. De cuyo proceso se obtuvo 85 artículos de potencial interés, al realizar la examinación por texto completo se eliminaron 72 estudios que no cumplían con los criterios de inclusión y con las expectativas y resultados esperados para la investigación. Llegando finalmente a la identificación de 13 referencias principales que cumplieron correctamente en los criterios de selección.

\subsection{Características de los estudios}

Los estudios incluidos en esta revisión, principalmente fueron publicaciones de los años 2015, 2018 y 2019. Se tomaron estudios de varios países primordialmente de Ecuador, Brasil y Colombia. La mayoría de los estudios se basan, en revisiones sistemáticas, análisis descriptivos, estudios de casos y aportaciones teóricas, hubo estudios que por el título del tema y resumen se centraban en los objetivos de la investigación en los cuales prevalecen las temáticas como objeto de estudio; la influencia de la filosofía católica en el cuidado humano, el aspecto del cuidado humanizado, la importancia de la religión en la enfermería del cuidado, el cristianismo y la medicina, la ética religiosa en el cuidado humano y la religión en la salud humana. Es pertinente mencionar que los estudios son de texto completo y están disponibles.

\section{Discusión}

\subsection{Resumen de evidencias}

Para este análisis se utilizado la herramienta RevMan.5, que por medio de las variables de estudio se logró la estratificación de los artículos incluidos, así nos permite conocer la homogeneidad o divergencia de los resultados entre los estudios, cuyo evaluación se presenta en la Tabla 3.

Tabla 3: Resumen de evidencias entre los estudios potenciales incluidos

\begin{tabular}{|c|c|c|c|c|c|c|}
\hline Autor-Año & Tema & Resultados & Similitud & Diferencia & Discrepancia & Complementación \\
\hline $\begin{array}{l}\text { Toma D., en- } \\
\text { tre otros - } \\
2020\end{array}$ & $\begin{array}{l}\text { Pasado y presente } \\
\text { de la función en- } \\
\text { fermera en el acto } \\
\text { del cuidado }\end{array}$ & $\begin{array}{l}\text { La enfermería es vital para el cuidado, } \\
\text { esta debe considerar las capacidades y } \\
\text { diversas costumbres y crecías que per- } \\
\text { mitan formar vínculos en bien de la sa- } \\
\text { lud, y a apreciar los cuidados humanos } \\
\text { desde una perspectiva de atención de } \\
\text { confianza }\end{array}$ & Moderada & $\begin{array}{c}\text { Baja, entre } \\
\text { estudios un } \\
20.33 \%\end{array}$ & $\begin{array}{c}\text { Bajo, } 14.5 \% \\
(0.145)\end{array}$ & $36.7 \%$, Sí \\
\hline
\end{tabular}


Tabla 3: Resumen de evidencias entre los estudios potenciales incluidos...continuación

\begin{tabular}{|c|c|c|c|c|c|c|}
\hline Autor-Año & Tema & Resultados & Similitud & Diferencia & Discrepancia & Complementación \\
\hline $\begin{array}{l}\text { Dora D., en- } \\
\text { tre otros - } \\
2018\end{array}$ & $\begin{array}{l}\text { Valores religiosos } \\
\text { y morales como } \\
\text { factores en el } \\
\text { desenvolvimiento } \\
\text { de enfermería }\end{array}$ & $\begin{array}{l}\text { La enfermería y la religión son dos as- } \\
\text { pectos de importancia, para proveer cui- } \\
\text { dados de calidez y de empatía ante la } \\
\text { situación de enfermedad - recuperación }\end{array}$ & Moderada & $\begin{array}{c}\text { Baja, entre } \\
\text { estudios un } \\
15 \%\end{array}$ & $\begin{array}{l}\text { Moderada, } \\
33.14 \% \\
(0.3314)\end{array}$ & $15.6 \%$, No \\
\hline $\begin{array}{l}\text { Patricia R., } \\
\text { entre otros - } \\
2018\end{array}$ & $\begin{array}{l}\text { El cuidado y la } \\
\text { enfermería }\end{array}$ & $\begin{array}{l}\text { El cuidado al ser práctico, acogido por } \\
\text { fuerzas espirituales y del entorno, ex- } \\
\text { presan el progreso del cuidado diferen- } \\
\text { ciado y convertido en compromiso de } \\
\text { profesionales. Las doctrinas hipotéticas } \\
\text { de la filosofía respeto a la atención de } \\
\text { la enfermería han provisto a esta área el } \\
\text { conocimiento para conceptuar el cuida- } \\
\text { do }\end{array}$ & Fuerte & $\begin{array}{c}\text { Baja, entre } \\
\text { estudios un } \\
8 \%\end{array}$ & $\begin{array}{l}\text { Bajo, } \\
21.05 \% \\
(0.2105)\end{array}$ & $78.25 \%$, Sí \\
\hline $\begin{array}{l}\text { Aquichan - } \\
2015\end{array}$ & $\begin{array}{l}\text { Enfermería en el } \\
\text { mundo cristiano }\end{array}$ & $\begin{array}{l}\text { La atención y el afecto a los necesitados } \\
\text { y moribundos. La enfermería percibe la } \\
\text { filosófica católica en la entrega de valo- } \\
\text { res como la ayuda, el respeto por la vida } \\
\text { y el compasión son aseverados la dogma } \\
\text { de creencia en Dios para la atención de } \\
\text { las personas }\end{array}$ & Fuerte & $\begin{array}{l}\text { Moderada, } \\
\text { entre } \\
\text { estudios un } \\
36.4 \%\end{array}$ & $\begin{array}{c}\text { Bajo, } 13.5 \% \\
(0.135)\end{array}$ & $81.63 \%$, Sí \\
\hline $\begin{array}{l}\text { González S. } \\
-2015\end{array}$ & $\begin{array}{l}\text { La enfermería y } \\
\text { la religión }\end{array}$ & $\begin{array}{l}\text { La salud y religión espiritualidad, son } \\
\text { pilares para las creencias religiosas, y } \\
\text { desarrollo de hábitos de salud y deter- } \\
\text { minar reglas en beneficio de la salud. }\end{array}$ & Fuerte & $\begin{array}{c}\text { Baja, entre } \\
\text { estudios un } \\
8 \%\end{array}$ & $\begin{array}{c}\text { Bajo, } 9.64 \% \\
(0.964)\end{array}$ & $34.14 \%$, Sí \\
\hline $\begin{array}{l}\text { María R., en- } \\
\text { tre otros - } \\
2017\end{array}$ & $\begin{array}{l}\text { Fundamentos } \\
\text { fenomenológicos } \\
\text { para un cuidado } \\
\text { comprensivo de } \\
\text { enfermería }\end{array}$ & $\begin{array}{l}\text { La experiencia conlleva a formar crite- } \\
\text { rios apegados a la conciencia, que se } \\
\text { imparte por medio del vínculo de con } \\
\text { la enfermería contribuyen a difundirlos, } \\
\text { en lo cual la asistencia que sea de em- } \\
\text { patía, flexibiliza los procesos e incluso } \\
\text { incentivan la congregación de los suje- } \\
\text { tos involucrados, dese la condición de } \\
\text { impotencia desfavorece la salud y limita } \\
\text { prácticas que hacen camino para nuevas } \\
\text { oportunidades de salud. }\end{array}$ & Moderada & $\begin{array}{l}\text { Baja, entre } \\
\text { estudios un } \\
6.39 \%\end{array}$ & $\begin{array}{l}\text { Bajo, } \\
25.31 \% \\
(0.2531)\end{array}$ & $58.23 \%$, Sí \\
\hline $\begin{array}{l}\text { María D., en- } \\
\text { tre otros - } \\
2018\end{array}$ & $\begin{array}{l}\text { Filosofía de } \\
\text { la ciencia del } \\
\text { cuidado analogía } \\
\text { del mito de la } \\
\text { caverna de platón } \\
\text { con la profesión } \\
\text { de enfermería }\end{array}$ & $\begin{array}{l}\text { La enfermería es una disciplina en cons- } \\
\text { tante cambio, que se desenvuelve con- } \\
\text { forme surten los procesos étnicos, epi- } \\
\text { démicos, sociales, familiares, y demás } \\
\text { cuyo origen surge de la humanidad al } \\
\text { constituir una práctica asumida e inhe- } \\
\text { rente para el cuidado por siglos, que la } \\
\text { venido creciendo desde su praxis teórica } \\
\text { hasta el despliegue de sus versiones de } \\
\text { filosofía y nociones originales }\end{array}$ & Moderada & $\begin{array}{l}\text { Moderada, } \\
\text { entre } \\
\text { estudios un } \\
56.82 \%\end{array}$ & $\begin{array}{c}\text { Bajo, } 7.32 \% \\
(0.0732)\end{array}$ & $35.78 \%$, No \\
\hline $\begin{array}{l}\text { Gabriela I. - } \\
2018\end{array}$ & $\begin{array}{l}\text { Bioética y cato- } \\
\text { licismo: dificulta- } \\
\text { des en torno a } \\
\text { la constitución de } \\
\text { una identidad co- } \\
\text { lectiva }\end{array}$ & $\begin{array}{l}\text { La ciencia en términos de la biomedici- } \\
\text { na, consiente a la religión como elemen- } \\
\text { to promotor en procurar la vida a través } \\
\text { de investigación y observación de los } \\
\text { adelantos en la medicina y el derecho, lo } \\
\text { cual sustenta como el ámbito pertinente } \\
\text { para definir nociones de la filosofía y an- } \\
\text { tropología, conforme a las percepciones } \\
\text { de inicio y termino de la vida estipula- } \\
\text { das y considerando la dimensión de ser } \\
\text { humano en general }\end{array}$ & Fuerte & $\begin{array}{l}\text { Fuerte, entre } \\
\text { estudios un } \\
75.21 \%\end{array}$ & $\begin{array}{c}\text { Moderada, } \\
64.23 \% \\
(0.6423)\end{array}$ & $53 \%$, Sí \\
\hline $\begin{array}{l}\text { Rosa G., en- } \\
\text { tre otros - } \\
2019\end{array}$ & $\begin{array}{l}\text { Cuidado humani- } \\
\text { zado de enferme- } \\
\text { ría según la teoría } \\
\text { de Jean Watson }\end{array}$ & $\begin{array}{l}\text { El cuidado enfocado con prioridad en } \\
\text { el enfermo, a las dolencias físicas y } \\
\text { psicológicas, esclarecen el factor espiri- } \\
\text { tual del paciente enfermo respecto a sus } \\
\text { dogmas, tradiciones y religión, como } \\
\text { aquello que permite acercase a la acción } \\
\text { del cuidado humano y la pretensión de } \\
\text { atribuir ayuda práctica con una atención } \\
\text { cimentada en la sensibilidad y empatía, } \\
\text { haciendo hincapié en una comunicación } \\
\text { positivista fundada en la esperanza y la } \\
\text { fe }\end{array}$ & Fuerte & $\begin{array}{l}\text { Baja, entre } \\
\text { estudios un } \\
27.53 \%\end{array}$ & $\begin{array}{c}\text { Moderada, } \\
57.95 \% \\
(0.5795)\end{array}$ & $45.36 \%$, No \\
\hline
\end{tabular}


Tabla 3: Resumen de evidencias entre los estudios potenciales incluidos...continuación

\begin{tabular}{|c|c|c|c|c|c|c|}
\hline Autor-Año & Tema & Resultados & Similitud & Diferencia & Discrepancia & Complementación \\
\hline $\begin{array}{l}\text { Daniel G., } \\
\text { entre otros - } \\
2016\end{array}$ & $\begin{array}{l}\text { Modelo de cuida- } \\
\text { dos de enfermería } \\
\text { para un entorno } \\
\text { multicultural }\end{array}$ & $\begin{array}{l}\text { El trabajo científico sobre la religión } \\
\text { y su impacto en la salud mental del } \\
\text { hombre, confirmando el efecto positivo } \\
\text { de la religión en la salud mental, social } \\
\text { y física. La religión y la espiritualidad } \\
\text { son aspectos importantes de la salud y } \\
\text { afectan la calidad de la vida humana }\end{array}$ & Fuerte & $\begin{array}{c}\text { Baja, entre } \\
\text { estudios un } \\
18.63 \%\end{array}$ & $\begin{array}{c}\text { Bajo, } 4.25 \% \\
(0.0425)\end{array}$ & 85.47 \%, Sí \\
\hline $\begin{array}{l}\text { Ángel D., en- } \\
\text { tre otros - } \\
2018\end{array}$ & $\begin{array}{l}\text { Cristianismo y la } \\
\text { medicina }\end{array}$ & $\begin{array}{l}\text { La aparición del cristianismo significa- } \\
\text { ría para la medicina, desde el punto de } \\
\text { vista ético, la introducción de una do- } \\
\text { ble noción antropológica la condición } \\
\text { personal y espiritual de la persona y } \\
\text { la concepción del amor hacia ella que } \\
\text { entrañaría una influencia benefactora en } \\
\text { el cuidado asistido }\end{array}$ & Fuerte & $\begin{array}{l}\text { Moderada, } \\
\text { entre } \\
\text { estudios un } \\
65.24 \%\end{array}$ & $\begin{array}{c}\text { Moderada, } \\
42.17 \% \\
(0.4217)\end{array}$ & $22.3 \%$, No \\
\hline $\begin{array}{l}\text { Yojanán R. - } \\
2019\end{array}$ & $\begin{array}{l}\text { La religión y su } \\
\text { influencia en las } \\
\text { conductas de sa- } \\
\text { lud }\end{array}$ & $\begin{array}{l}\text { Se prescinde que las, dogmas religiosas } \\
\text { inciden en disciplinar el comportamien- } \\
\text { to humano, desde la manera de alimen- } \\
\text { tarse, de socializarse con las personas } \\
\text { entre otros. Es por ello que la psicolo- } \\
\text { gía estudia este efecto, que sostiene la } \\
\text { pericia religiosa en la salud evidencias } \\
\text { existen sobre su estrecha relación }\end{array}$ & Fuerte & $\begin{array}{c}\text { Baja, entre } \\
\text { estudios un } \\
2.35 \%\end{array}$ & $\begin{array}{c}\text { Bajo, } \\
15.24 \% \\
(0.15 .24)\end{array}$ & $73.13 \%$, Sí \\
\hline $\begin{array}{l}\text { Jesús P., en- } \\
\text { tre otros - } \\
2020\end{array}$ & $\begin{array}{l}\text { Introducción } \\
\text { a la relación } \\
\text { entre cuidado y } \\
\text { filosofía }\end{array}$ & $\begin{array}{l}\text { Es imprescindible que la religión y la } \\
\text { enfermería deban afianzarse más, por } \\
\text { ser conformemente relacionadas a un } \\
\text { propósito común, pero esta propuesta } \\
\text { no es del todo tomada en cuenta en la } \\
\text { práctica, con precisión se conoce que la } \\
\text { percepción de la salud de las personas } \\
\text { involucra la religiosidad, por ende se re- } \\
\text { conoce su importancia para las personas }\end{array}$ & Moderada & $\begin{array}{l}\text { Moderada, } \\
\text { entre } \\
\text { estudios un } \\
54.18 \%\end{array}$ & $\begin{array}{c}\text { Bajo, } 2.36 \% \\
(0.0236)\end{array}$ & 45.17 \%, Sí \\
\hline
\end{tabular}

Nota: «En esta tabla se describe la información relevante de cada estudio seleccionado, la información expuesta fue adaptada por los autores en base a los fuentes de estudios incluidos en esta revisión. Tomada de:(Dandicourt Thomas et al., 2017; Dueñas, 2016; Irrazábal, 2015; Momennasab et al., 2019; Neil Cope et al., 2016; Puelma C. \& Donoso M., 2014; Quintero Laverde, 2015; Rivera \& Herrera, 2016; Rocha et al., 2019; Rodríguez, 2015; G. Sanz, 2016; Tapia \& Guzmán, 2018; Żołnierz \& Sak, 2017)»

\subsection{Sustentación teórica}

Según la evaluación en los resultados de los estudios incluidos, en la apreciación de las variables de estudio, se obtuvo un valor de moderado a fuerte conforme a las similitudes con las muestras representativas del análisis. En lo cual se identificaron 8 estudios de calidad fuerte y 5 de ellos de calidad moderada. Siendo así esta atribución respecto al nivel símil entre los estudios. Se apreció como factor más relevante de esta característica que la filosofía católica en el cuidado humano, involucra la incursión en directrices desde dos aspectos, el primero la influencia de la religión en el condicionamiento de conductas saludables en las personas, percibiendo en ellos, sus valores, creencias y costumbres. ${ }^{26,39}$ La segunda en la enfermería que al ser por excelencia dedicada al cuidado humano, tiene en cuenta la religión como parte de los valores de la disciplina por tener empatía y apoyo a los enfermos y con los que necesitan cuidados por amor al prójimo, a consecuencia de recuperar y cuidar su salud de una forma cálida y sensible a tal punto de que este proceso sea grato. 1,14,21,22,26 Por lo que ambos criterios reflejan la parte humanitaria, en el cuidado de las personas desde el punto de vista de la religión, creencias católicas, y la influencia del cristianismo, como factores que promueven la recuperación y el cuidado, en provecho de la salud de las personas.

Las diferencias entre los resultados atribuidos por las referencias, se establecieron en un rango de bajo a alto nivel, por lo cual se observó que 8 de los estudios tienen un nivel bajo, 4 estudios un nivel moderado y 1 estudio un nivel fuerte. Por lo que la disimilitud de los resultados entre los estudios incluidos, estima una representación global del $26.3 \%$ la cual podemos catalogarla como un factor de diferencia despreciable en los resultados. De los estudios rescatados la diferencia de los resultados se relaciona en las diversas costumbres, culturas, creencias y a factores éticos, morales y espirituales de las personas de diferentes regiones. ${ }^{4,11,17,33,40}$ Se evidencia que la religión en el cuidado humano, se sitúa en un aspecto de la pretensión social y cultural de como se aprecia la dignidad humana, al relacionar el cuidado humano con el amor y compasión del ser supremo representado en nuestro Dios, en los cuidados que el ofrecía a los indefensos y enfermos y con la bondad y calidez, a los cuales asistía, hacen concebir al cuidado y a religión como nociones estrechamente relacionadas. ${ }^{1,13-15,22,44}$ Razón por la cual le otorga una categoría especial de valor sagrado para la vida humana, sin embargo la condición social se convierte en un ente 
que hace diferencia en los resultados al otorgar a ciertos grupos en virtud de su posición o status social el cuidado, por lo cual la dignidad humana pierde su valor absoluto y sagrado convirtiéndose en un asunto relativo y social, siendo el principal contraste en el cuidado humano.

En el análisis las discrepancias de los datos acontecidos, señalan un $24 \%$ de disconformidades, los cuales en mayor medida son con respecto a las creencias y status social. En los diversos ámbitos, que emana el cuidado de las personas, la filosofía católica infringe en las cualidades pertenecientes a todos los seres humanos sensibles y como es de suponer la libertad moral. ${ }^{20,32,38,43,45}$ Lo cual involucra en estar dispuestos a la comprensibilidad y el respecto encaminados a la calidad para llevar una vida digna que no solo es una cuestión de salud sino también de convivencia, ya que los principios de la religión católica definen como aspecto central el carisma para el cuidado de las personas, siendo esta propuesta extensible, que además es contemplada por el área de la salud como la enfermería en proveer cuidados gratos a las personas respetando sus creencias, valores y religión por el hecho de que las atenciones sean visto opacadas e interferidas por la ciencia en el desarrollo tecnológico que dejan de lado el verdadero significado del cuidado humano y dejando de ser el centro de la asistencia las personas convirtiéndose en intervenciones frías y poco afables para el cuidado de calidad, siendo de vital importancia la apropiación de fundamentar los principios de la religión cristina en el cuidado y protección de la salud social.

La complementariedad del estudio, señala una significativa relación con los resultados aportados con los cuales podemos abordar y tener en cuenta varios ámbitos de la filosofía católica en el cuidado humano, pues se tiene que en consecuencia la religión permite generar la conciencia por el propio cuidado para mantener una vida saludable y digna, evitando ser objeto de presunción y discriminación social, de tal manera que el cristianismo asigna valores éticos y morales, por amor y cuidado propio y al prójimo, evitando aspectos perjudiciales en la salud, considerando que el ser humano reciba un trato respetuoso y no interfieran estratos sociales. ${ }^{8,19,30,36,41}$ Por lo que deben ser las personas el punto de atención y no como un medio de algo subjetivo. Del mismo modo esta propuesta también es acogida y resulta base fundamental en el área de la salud, caso concreta de la enfermería para ofrecer atenciones que sean de calidad para los pacientes enfermos, en tratar de establecer vínculos que permitan la interacción a tal punto de comprender y conocer la situación de las personas y así ayudarles a mejorar y proteger la salud, con una atención que contemple todo lo que incurre el aspecto humano.

Como se aprecia la religión en el cuidado humano, encara no solo el ámbito social sino también de la enfermería cuyo propósito exclusivo en definitiva es preservar con calidad la dignidad humana para una vida plena, cuyas nociones se nutren en la conciliación de algunos conceptos que involucran a la bioética, la humanización de tal de forma que recibe matices que amplían de sobre manera el significado de la filosofía católica en la atención de las personas en condición de enfermedad o necesidad, en donde se refiere a la solidaridad, la bondad, la igualdad y la actitud de mutuo respeto. 2, 7,18,27,31 Siendo estos elementos el común de todo ser humano donde la subjetividad de cada persona prima en la dignidad para el cuidado tanto desde óptica social como de atención médica, siendo la principal aportación de la religión cristiana en el cuidado humano hacia la enfermería en dotar de estas características, para que la disciplina mantenga un servicio de calidad, respeto y sensibilidad humana por compasión a los enfermos siendo estas las áreas que debe avistarse en todo profesional de la salud. 9, 23, 28,29,37 La siguiente Figura 2, muestra la relación conceptual de los principios de la filosofía católica respecto al cuidado humano.

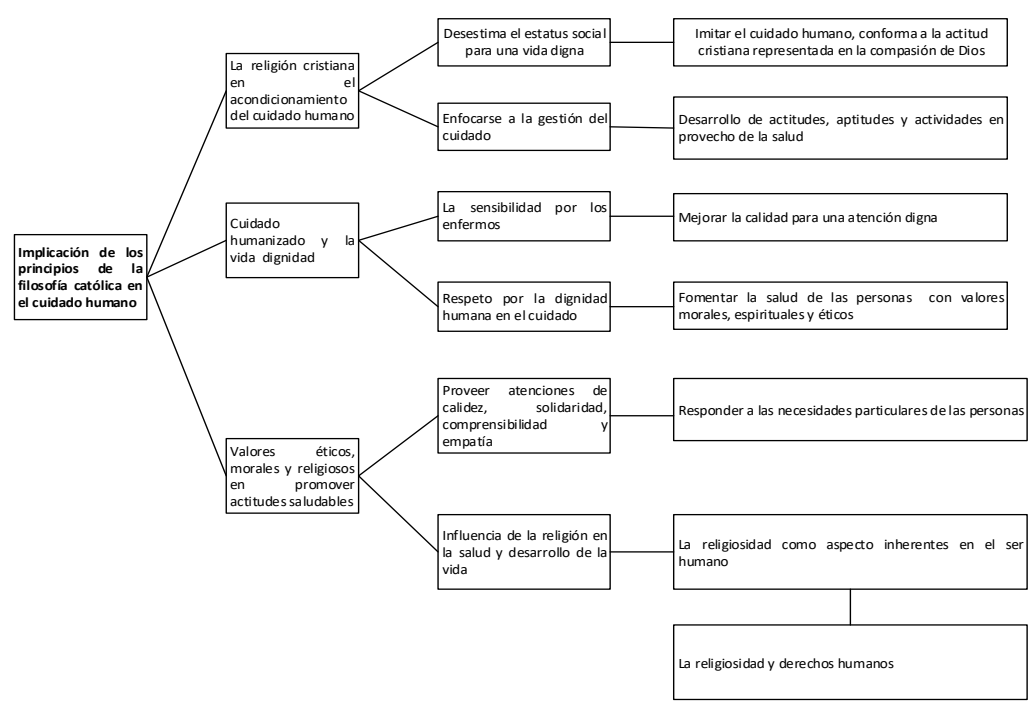

Fig. 2: Matriz de categorías de la filosofía católica en el cuidado humano Fuente: Autores 


\section{Conclusiones}

La religión es una forma donde las personas manifiestan su espiritualidad siendo aspecto inherente en éstas, en la cual se sabe que afecta la salud en forma positiva o negativa, según como esta influye en la existencia por el poder que tienen en el desarrollo de la vida de las personas.

En el escenario del cuidado humano, la contribución de los principios de la filosofía católica ha tenido gran interés y expectativa, al considerar todo el aspecto humano; desde el respeto mutuo, las creencias, cultura, principios morales, éticos y religiosos. En función de los cuales conforman al cuidado, como un asunto de la dignidad humana. Dado que se ha perdido la estima y sensibilidad por el cuidado de las personas y no tener en cuenta la condición especifica en la que se pueda hallarse ante necesidad o enfermedad. Siendo un tema subjetivo a estratos sociales concretos, en suponerlos como únicos merecedores de concebir un cuidado digno, que no están en el mismo contexto de lo que involucra la filosofía religiosa en las personas, puesto que el representante principal de los cuidados humanos dentro de la filosofía cristiana constituye Dios, cuyo accionar se ve envuelto en el amor al prójimo y la empatía por los demás, que vela por el bienestar de enfermos mediante el cuidado caritativo, respetuoso y solidario sin tener en cuenta su condición social, política y creencia. Esto hace que los principios religiosos condicionen el cuidado humano, al desarrollo del cuidado propio y evada los factores de riesgo que afecten la calidad de vida en las personas al crear conciencia, aptitudes, actitudes y actividades que contribuyan sobre la misma para conservar la salud de las personas. $3,20,26,28,34,40,45$

Sin duda a esta concepción, la enfermería es la que mayor apego pretende en el cuidado de las personas como parte inherente de su praxis, donde la atención debe ser vista desde todas las dimensiones del ser humano, donde la actitud y capacidad estén orientadas a la sensibilidad humana, apegadas al respecto, al derecho y a comprender que cada persona es única y se asocia a responder a necesidades particulares sin generalizarlas, donde la función compartida entre el enfermero y el paciente sano o enfermo es la planificación de actividades que fomente la salud.

Por ende el cuidado es una ciencia comprendida desde una base moral y filosófica entendida para la enfermería, en lo cual la filosofía religiosa tiene gran relevancia, pues menciona que el cuidado, no se limita a la ejecución de la capacidad técnica profesional y uso de equipos enmarcados, en un asunto de la asistencia social, seguimiento y conservación por la sanación de las personas, sino que va más allá de algo que envuelve una relación por gestionar el cuidado. ${ }^{11,24,29,35,38,39,41}$ De forma que el aspecto religioso suscita el cuidado humanizado no solo al aspecto profesional, son también a la habilidad por conocer y comprender al paciente respondiendo a sus esencias más profunda y exteriorizadas.

Aprehender la dignidad para el cuidado, es una necesidad tanto entendida desde la óptica social como de la salud, que apresta la atención de la gente como es la enfermería. Por lo que incurrir en la necesidad de que el cuidado humano implique la participación de la condición del aspecto de la filosofía católica, en como esta contribuye a proporciona una vida digna a través del cuidado humanizado, en lo cual el cuidado ha incidido en la deshumanización de tal forma que este se centra en el desarrollo de habilidades, técnicas y procedimiento que no sustentan en su totalidad las necesidades biopsicosociales y espirituales de las personas, pues existe evidencia de que los profesionales tiene mayor formación científica pero deficiencia en el trato amigables, de sensibilidad y delicado para cuidar a las personas.

\section{Fuente de Financiamiento}

Este estudio es autofinanciado.

\section{Conflicto de Intereses}

No existen conflictos personales, profesionales, financieroso de otro tipo.

\section{Consentimiento Informado}

Los autores cuentan con el consentimiento informado de los pacientes para la investigación, la publicación del caso y sus imágenes.

\section{Referencias Bibliográficas}

1. Neil Cope, C., Azofeifa Ugalde, E., \& Calderón Montero, L. (2016). Intervención del y la profesional de enfermería ante las necesidades religiosas de la persona hospitalizada. Enfermería En Costa Rica, 33(2), 58-65. Retrieved from http://www.binasss.sa.cr/revistas/enfermeria/v33n2/ art1.pdf

2. Żołnierz, J., \& Sak, J. (2017). Modern research on religious influence on human health. Journal of Education, Health, and Sport, 7(4), 100-112. https://doi.org/10.5281/ zenodo. 376746

3. Blanco Enríquez, F., Caro Castillo, C., Gómez Ramírez, O., \& Cortaza Ramírez, L. (2019). José, una mirada al ser: análisis de una narrativa de enfermería de acuerdo con el modelo de adaptación de Roy. Ene, 13(1), 13110. https: //doi.org/10.4321/s1988-348x2019000100010

4. Health, B. (2018). Proceedings of the 4th IPLeiria's International Health Congress. BMC Health Services Research, 18(S2). https://doi.org/10.1186/s12913018-3444-8

5. Baldacchino, D. (2015). Spiritual Care Education of Health Care Professionals. Religions, 6(2), 594-613. úrlhttps://doi.org/10.3390/rel6020594

6. Sanz, G. (2016). La enfermería y la religión. Retrieved from http://rabida.uhu.es/dspace/bitstream/handle/10272/ 11985/La_religion_y_su_influencia.pdf?sequence=2

7. Toker, K., \& Çinar, F. (2018). Perceptions of Spirituality and Spiritual Care of Health Professionals Working in a State Hospital. Religions, 9(10), 312. https://doi.org/10. 3390/re19100312 
8. Rincón Rueda, A. (2018). La religión y la formación de la civilidad. Sophía, (24), 171. https://doi.org/10.17163/21. soph.n24.2018.05

9. De Diego Cordero, R., Suero Castillo, C., \& Vega Escaño, J. (2019). La formación en religiosidad y espiritualidad 22 en los estudios de Grado en Enfermería. Cultura de Los Cuidados Revista de Enfermería y Humanidades, (53). https://doi.org/10.14198/cuid.2019.53.29

10. González, D. (2016). Buscando un modelo de cuidados de enfermería para un entorno multicultural. Gazeta de 23 . Antropología, 22, 1-14. Retrieved from https://www.ugr. 24. es/ pwlac/G22_32Daniel_Leno_Gonzalez.html

11. Dandicourt Thomas, C., Hernández Valdez, E., Espinoza Moreno, T. M., \& Pérez Siguas, R. E. (2017). Pasado y presente de la función enfermera en el acto del cuidado. 25 . Health Care \& Global Health, 1(1), 49-54. https://doi.org/ 10.22258/hgh.2017.10

12. Gijsberts, M., Liefbroer, A., Otten, R., \& Olsman, E. (2019). Spiritual Care in Palliative Care: A Systematic 26. Review of the Recent European Literature. Medical Sciences, 7(2), 25. https://doi.org/10.3390/medsci7020025

13. Thiengo, P., Gomes, A., Das Mercês, M., Couto, P., França, L. \& Da Silva, A. (2019). Espiritualidad e religiosidad no cuidado em saúde: Revisão integrativa. Cogitare Enfermagem, 24. https://doi.org/10.5380/ce.v24i0.58692

14. López-Tarrida, Á., Ruiz-Romero, V., \& González-Martín, 27. T. (2020). Caring with meaning: the spiritual care in healthcare from the professional's perspective I Cuidando con sentido: la atención de lo espiritual en la práctica clínica desde la perspectiva del profesional. Revista Espanola 28. de Salud Publica, 94.

15. Momennasab, M., Shadfard, Z., Jaberi, A., Saeed Najafi, S., \& Naeemi Hosseini, F. (2019). The Effect of group reflection on nursing students' spiritual well-being and attitude toward spiritual care: a randomized controlled 29. trial. Investigación y Educación En Enfermería, 37(1), e9. https://doi.org/10.17533/udea.iee.v37n1e09

16. Puelma C., D., \& Donoso M. (2017). Valores religiosos y morales como factores en el desenvolvimiento de enfermería. Revista Brasileira de Enfermagem, 29(3), 26-33.30. https://doi.org/10.1590/0034-716719760003000010

17. Rodríguez, Y. (2015). La religión y su influencia en las conductas de salud. Retrieved from http://rabida.uhu.es/dspace/bitstream/handle/10272/ 11985/La_religion_y_su_influencia.pdf?sequence=2

18. Irrazábal, G. (2015). Bioética y catolicismo: dificultades en torno a la constitución de una identidad colectiva. Religião \& Sociedade, 30(1), 101-116. https://doi.org/10. 1590/s0100-85872010000100006

19. Fajardo-Ramos, E., \& Henao-Castaño, A. (2019). Bien-32. Ferreres, L. (2017). La presencia de los valores en la estar Espiritual de los Estudiantes de Enfermería. Cultura de Los Cuidados Revista de Enfermería y Humanidades, 33. (54). https://doi.org/10.14198/cuid.2019.54.03

20. Puelma C., \& Donoso M. (2014). Valores religiosos y morales como factores en el desenvolvimento de enfer-

mería. Revista Brasileira de Enfermagem, 29(3), 26-33.34. Hefti, R., \& Esperandio, M. R. G. (2016). The Interdis- https://doi.org/10.1590/0034-716719760003000010

Flessa, S. (2016). Christian milestones in global health: The Declarations of Tübingen. Christian Journal for Global Health, 3(1), 11. https://doi.org/10.15566/cjgh.v3i1.96 Morillo Martín, M., Galán González-Serna, J., \& de Llanos Peña, F. (2017). Nurses attitudes to the spiritual and religious care in a general hospital | Actitudes de las Enfermeras ante los Cuidados Espirituales y Religiosos en un Hospital General. Index de Enfermeria, 26(3).

3. Dueñas, Á. (2016). Cristianismo y medicina (Vol. 165). desde la prespectiva católica. Journal of Chemical Information and Modeling, 53(9), 1689-1699. https://doi.org/ 10.1017/CBO9781107415324.004

. Rosa Gurrero Ramirez, M. (2015). Cuidado humanizado de enfermería según la teoría de Jean Watson. Retrieved from http://repositorio.ucv.edu.pe/bitstream/handle/UCV/ 19486/3017-7642-1-PB.pdf?sequence $=1 \&$ is Allowed=y

Sanz, J. (2016). La universidad como marco para una filosofía de la enfermería; The university as a frame for nursing philosophy. Retrieved May 7, 2020, from https://www.researchgate.net/publication/301295873_ La_universidad_como_marco_para_una_filosofia_de_ la_enfermeria_The_university_as_a_frame_for_nursing philosophy

7. Gómez Serna, J., \& Giraldo Zuluaga, C. (2019). De la "Cura amoris" en Pascal, un vistazo ético-antropológico a “Les Pensées.” Escritos, 27(59), 198-221. https://doi.org/ 10.18566/escr.v27n59.a01

Rocha, P., Do Prado, M., De Gasperi, P., Sebold, L., Waterkemper, R., \& Bub, M. (2019). El cuidado y la enfermería. Care and Nursing. (English), 27(1), 102-109. Retrieved from http://search.ebscohost.com/login.aspx?direct= true $\& \mathrm{db}=$ fua $\& \mathrm{AN}=44530114 \&$ lang=es \&site=ehost-live

Unicef. (2016). ¿Cómo se relacionan la enfermería y la religión? - Diario Dicen. Retrieved April 23, 2020, from https://www.enfermeria21.com/diario-dicen/comose-relacionan-la-enfermeria-y-la-religion-ddimport056223/

. Tapia, W., \& Guzmán, S. (2018). Cuidado humanizado desde la percepción del paciente, familiar cuidador y enfermero. Hospital I el Buen Samaritano - Essalud 2017 Tesis.

31. Díaz Rentería, M. (2016). Filosofía de la ciencia del cuidado. Analogía del mito de la caverna de Platón con la profesión de enfermería / Philosophy of science of caring the allegory of the cave by plato with the nursing profession. RICS Revista Iberoamericana de Las Ciencias de La Salud, 2(3), 21. https://doi.org/10.23913/rics.v2i3.17 práctica enfermera.

. Rivera, M., \& Herrera, L. (2016). Fundamentos fenomenológicos para un cuidado comprensivo de enfermería. Texto \& Contexto - Enfermagem, 15(spe), 158-163. https: //doi.org/10.1590/s0104-07072006000500019
Hechavarría, Rodney; López, G. (2016). Cuidado humano 
ciplinary Spiritual Care Model - A holistic Approach to Patient Care. HORIZONTE, 14(41), 13. https://doi.org/ 4 10.5752/P.2175-5841.2016v14n41p13

35. Martins, A. (2019). Ética social católica e saúde pública: Em busca de uma bioética libertadora. Perspectiva Teológica, 51(3), 461. https://doi.org/10.20911/ 21768757v51n3p461/2019

36. O'Neill, D. (2017). Practice and presence: a gathering for Christians in health care - finding God in all 4 things. Christian Journal for Global Health, 4(2), 103. https://doi.org/10.15566/cjgh.v4i2.185

37. Quintero Laverde, M. (2015). Enfermería en el mundo cristiano. Aquichan, 42-45.

38. Rudilla García, D., Barreto Martín, P., \& Oliver, A. (2015). 4 Teoría y práctica de la dignidad en cuidados paliativos: una revisión. Psicooncología, 11(1). https://doi.org/10. 5209/rev_PSIC.2014.v11.n1.44913

39. Giménez Béliveau, V., Irrazábal, G., \& Griera, M. (2018). Salud y religiones: prácticas y sentidos en diálogo y disputa. Salud Colectiva, 14(2), 153. https://doi.org/10.18294/ sc. 2018.1958

40. Aguiar, N., Meira, D., \& Raquel, S. (2015). Study on the efficacy of the Portuguese cooperative taxation. REVESCO Revista de Estudios Cooperativos, 121, 7-32. https: //doi.org/10.5209/rev

41. Guerrero-Ramírez, R., Riva, E. M.-L., De, M., \& CruzRuiz, L. (2016). Cuidado humanizado de enfermería según la teoría de Jean Watson, servicio de medicina del Hospital Daniel Alcides Carrión. Lima- Callao. In Rev enferm Herediana (Vol. 9).

. Pinto Freyre, J., Santamaría García, J., Santamaría Pérez, A., \& Martínez Botija, S. (2017). Cuidadosofía: una introducción a la relación entre cuidado y filosofía. Ene, 11(3). Retrieved from http://www.ene-enfermeria.org/ojs/index. $\mathrm{php} / \mathrm{ENE} /$ article/view/735/cuidadosofia

43. Hospicio, D. E. (2017). El cuidado cuando no podemos curar.

4. Arriaga-García, A., \& Obregón-De La Torre, M. (2019). Conocimientos y actitudes sobre el cuidado humanizado en enfermeras de Lima. CASUS. Revista de Investigación y Casos En Salud, 4(2), 102-110. https://doi.org/10. 35626/casus.2.2019.213

. Nathan, A., \& Scobell, A. (2016). Cuidados humanos desde la marco de la Filosofía Católica. Foreign Affairs, Vol. 91, p. 287. https://doi.org/10.1017/CBO9781107415324. 004

Recibido: 20 de junio de 2020

Aceptado: 10 de noviembre de 2020

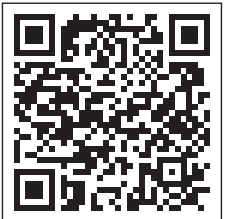

